\title{
Characterizing Mathematics Learning in Colombian Higher Distance Education
}

\author{
Elizabeth Martinez-Villarraga ${ }^{1, * \mathbb{D}}$, Isabel Lopez-Cobo ${ }^{2} \mathbb{D}$, David Becerra-Alonso ${ }^{3}$ (D) and Francisco \\ Fernández-Navarro ${ }^{3}$ (i) \\ 1 Facultad de Ciencias y Tecnologías, Universidad Santo Tomás, Bogota 110231, Colombia \\ 2 Departamento Didáctica y Organización Educativa, Universidad de Sevilla, 41004 Sevilla, Spain; \\ ilopez10@us.es \\ 3 Department of Quantitative Methods, Universidad Loyola Andalucía, 41704 Dos Hermanas, Spain; \\ dbecerra@uloyola.es (D.B.-A.); fafernandez@uloyola.es (F.F.-N.) \\ * Correspondence: elizabeth.martinez@ustadistancia.edu.co
}

Citation: Martinez-Villarraga, E.; Lopez-Cobo, I.; Becerra-Alonso, D.; Fernández-Navarro, F. Characterizing Mathematics Learning in Colombian Higher Distance

Education. Mathematics 2021, 9, 1740. https://doi.org/10.3390/math9151740

Academic Editors: Jarmila Novotná and Alena Hošpesová

Received: 7 July 2021

Accepted: 20 July 2021

Published: 23 July 2021

Publisher's Note: MDPI stays neutral with regard to jurisdictional claims in published maps and institutional affiliations.

Copyright: (c) 2021 by the authors. Licensee MDPI, Basel, Switzerland. This article is an open access article distributed under the terms and conditions of the Creative Commons Attribution (CC BY) license (https:/ / creativecommons.org/licenses/by/ $4.0 /)$.

\begin{abstract}
The aim of this work is to characterize the process of constructing mathematical knowledge by higher education students in a distance learning course. This was done as part of an algebra course within engineering degrees in a Colombian university. The study used a Transformative Sequential Design in mixed methods research. The analysis also determined the kinds of mathematical knowledge attained by the students and its relationship to the Colombian social and cultural context. The students acquired declarative, procedural, and conditional knowledge, while the learning strategies were often superficial. In a context where power is distant, students take on a passive approach to learning despite being highly respectful towards the educator. Thus, the educational system has the educator at the center.
\end{abstract}

Keywords: learning mathematics; higher education; distance education; cultural dimension

\section{Introduction}

Distance education has been one of the main alternatives for many people to access the educational system. At the writing of this article, worldwide educational institutions are facing preventive and mandatory closures due to the SARS-CoV-2 pandemic. In the educational sector, teachers from elementary schools to higher education levels have had to adapt to online learning settings as students have faced the closures of educational institutions [1]. This adaption has been incredibly challenging, especially in developing countries, where teachers and organizations, in some cases, do not have the proper means to implement distance education lectures effectively [2]. For example, a recent study that analyzed vital elements, from the instructor's point of view, in the transition from faceto-face learning to online learning reported that traditional instructors have difficulties implementing the role of life skills promoter (relevant according to the UNESCO humanistic vision of universities) [3]. Following UNESCO's suggestions, many institutions have taken advantage of the benefits provided by technologies common to distance education. This model has thereby taken on a new relevance.

However, it has faced a great controversy regarding its quality. The concept of quality in online learning has been measured from three different perspectives: quality control, quality assurance, and quality improvement [4]. There are several fundamental approaches to quantifying the quality of online learning programs in the online learning literature [5]. Among the vast number of studies, it is worth mentioning the 24 benchmarks for success in Internet-based distance education: Khan's eight dimensions of e-learning framework, Sloan Consortium's (Sloan-C) five pillars of quality, Osika's concentric model, and Moore and Kearsley's assessment recommendations [6]. According to Auster (2016) [7], an error is made when we compare and measure it by the same standards as regular education. The learning of students isolated from their teacher has also been put into question [8]. 
Another difficulty faced by distance education is the high student drop-out rate. The definition of dropout in online learning is very tough, as students enrolling in online learning programs are typically adult learners with work and family commitments (additional to those of continuing learning) and therefore with a natural tendency to take academic breaks [9]. As pointed out in Gomez-Rey, Barbera, and Fernández-Navarro (2016) [5], instructor interaction helps to reduce the high dropout rate in online learning and increases students' motivation. This is a crucial component within the online learning scenario. In Colombia, the country where this research was done, according to figures from the Ministry of Education (MEN) for 2019, distance education programs have a 60\% drop out rate. This is one of the main problems affecting the higher education system in the country (CEDE. (2014). Determinants of dropout. https:/ / www.mineducacion.gov.co/ sistemasdeinformacion/1735/articles-254702_Informe_determinantes_desercion.pdf, accessed on 10 July 2021).

According to Sweet (1986) [10], several models have been proposed and adapted from Tinto's proposal to explain desertion in regular education: psychological [11], sociological [12], economic [13], organizational [14], and adaptation and integration [15] models. Numerous variables have been considered, such as personality traits, social integration, and work activity, to explain the high rates of course failure. Basic sciences (mathematics, physics, statistics, chemistry, etc.) are embedded in most adult education programs worldwide. These courses are the ones returning a larger number of failing grades and motivate a higher drop-out rate.

Parker (1999) [16] carried out their research specific to one of these variables. They argue that students required to have a high level of quantitative reasoning do not pass their first math courses. The National University of Costa Rica [17] showed in its report that $30 \%$ of the students who enroll in the subject of mathematics drop out, and $23 \%$ repeat it three or more times. In Colombia, a student can repeat this subject up to 11 times, according to a recent study [18].

"Learning", as understood by Vygotski (1978) [19], is the process of building knowledge immersed in collective contexts and carried out by teachers and students in a specific environment. This approach has been a subject of great interest for many years in fields such as psychology, pedagogy, and didactics. Multiple publications characterize the types of knowledge common to mathematics. Although there are many studies for students in regular education at primary and secondary education levels [20-22], very few can be found for higher education and adults [23,24]. Particularly limited is the number of publications in the Colombian context.

It is common in distance education to find students from different countries or regions. This may have an influence on how students learn or relate to each other and to their tutor. This is detailed in Hofstede (2001) [25], who made a model of six cultural dimensions that tries to identify the cultural behaviors of a country in order to better understand their culture. Bearing in mind that the academic success of students is closely related to the way students learn, we propose the following objectives:

- Identifying the type of mathematical knowledge produced by students in higher distance education in Colombia.

- Describing how students build mathematical knowledge in higher distance education in Colombia.

Additionally, the empirical results found in the study will be justified through Hofstede's (2001) [25] model of cultural dimensions. These data will allow a better understanding of the learning process of mathematics learning in distance education, specific to Colombia. It will also provide guidelines to improve the desertion rates.

\section{Literature Review}

In educational mathematics, the social construction of knowledge incorporates four dimensions: its epistemological nature, its sociocultural dimension, cognitive development and modes of transmission [26]. This work will focus on sociocultural dimensions and 
cognitive planes to describe the construction process and the types of knowledge being made in mathematics learning. Although there is no consensus on the definition of different types of knowledge, there are several characterizations that are derived from the work of Johnson (2005) [27].

\subsection{Types of Mathematical Knowledge}

2.1.1. Declarative Knowledge

Declarative knowledge is generated by schemes that he calls presentative. These allow the understanding of underlying reasons. It is conceptual and is generally compared to deep, flexible, and highly connected knowledge. It is made of a set of concepts, principles, and theories, as well as the reasoning by which they were reached. For Johnson (2005) [27], this knowledge refers to a wide network of relationships between information units, a kind of normative knowledge. Star (2005) [28] states that "the term conceptual knowledge has come to encompass not only what is known (knowledge of concepts) but also one way that concepts can be known (e.g., Deeply and With Rich Connections)" (p. 408). Unlike previous authors, Baroody et al. (2007) [29] do mention that this knowledge is related. They consider it only as a knowledge of facts (generalizations) and principles. In mathematics, this type of knowledge is strongly related to its inner aspects and the representation and notation systems used to communicate ideas.

\subsubsection{Procedural Knowledge}

Procedural knowledge is generated by schemes that Johnson called procedures. It yields the means to do something. It is associated with an automated knowledge, poorly connected and shallow, as it comprises the procedures to address a problem situation (know-how). This knowledge uses various sequences of actions and operations according to an end that, depending on the complexity of the problem at hand, might turn into a set of procedural chains. For Johnson (2005) [27], this knowledge involves a formal language or representation system and rules or algorithms that guide the individual towards the solution of a problem. It is thus similar to a pragmatic type of knowledge. To Star (2005) [28], this knowledge is not superficial. Star maintains that by acquiring the procedures, they become routines. When fluently executed, a specific piece of knowledge has been automated, thus becoming deep in nature. Contrary to this position, RittleJohnson et al. (2015) [30] describes it as the ability of students to carry out actions that allow them to solve problems. Here, we have a knowledge that is linked to specific problems and not necessarily generalizable.

In mathematics, there are two types of procedures: algorithmic and heuristic. The former leads to the correct solution of an exercise when the pre-defined steps are followed. The latter does not guarantee a correct solution; it only systematically defines the steps to approach it.

\subsubsection{Conditional Knowledge}

Although there are only two cognitive subsystems (understanding and know-how) in mathematics according to Johnson (2005) [27], a third group of schemes called operative schemes is also commonly used. These schemes allow a presentative and procedural linking of knowledge items. Rittle-Johnson and Alibali (1999) [31] argue that declarative and procedural knowledge are not independently developed. They consider conditional knowledge as the kind linked by both declarative and procedural knowledge. It is part of a self-regulated learning, since the student demands to learn how to improve learning. This provides an indicator of how much the student knows and what the limitations are.

Rittle-Johnson et al. (2015) [30] claim that it is not easy to separate the declarative knowledge from the procedural one. It is, however, very useful to differentiate them and distinguish their particularities in order to understand their interactions in a problemsolving scenario. 


\subsection{Process of Construction of Mathematical Knowledge}

From a sociocultural viewpoint, the construction of mathematical knowledge requires specific contexts that allow interaction, negotiation and communication with others to construct meanings. This initially implies individual work in which the student faces a cognitive conflict, and then, through collective work where co-construction and participation is vital, the redefinition and validation of constructed knowledge is favored. Here, knowledge and communication are two inseparable and interdependent processes. In an educational context, the analysis of the interactions present in classrooms has been approached from the perspectives of sciences such as anthropology, sociology, didactics, linguistics, psychology, and others. This analysis has become a valuable instrument to study the teacher-student and student-student communication processes, where knowledge is built and validated.

Cubero and Ignacio (2011) [32] argue that the discourse present in interactions is not only the means by which messages are transmitted, but also the activity where meanings are constructed. Therefore, discourse analysis facilitates an approach to the reality of classrooms suitable to understanding the processes that take place there. According to Prados and Cubero (2013) [33], any classroom is a setting that allows the construction and validation of knowledge. These validations are not pre-established. They are generated and transformed via different interactions throughout the communication process. Each activity carried out in the classrooms is a process of creation of shared meanings. From this perspective, the teaching-learning process is a co-construction process. It involves conceptions, ideas, beliefs, and both personal and collective knowledge that facilitate the assimilation of new knowledge.

\subsection{Hofstede's Cultural Dimensions}

Hofstede (2001) [25] defines culture in their work "The Consequences of Culture" as the collective programming of the mind that distinguishes the members of one group or category of people from another. His research on the differentiation between cultures led them to construct six cultural dimensions. In this section, Hofstede's values for Colombia were analyzed. These were extracted from the Hofstede insights webpage (Hofstede insights webpage: https: / /www.hofstede-insights.com/, accessed on 10 July 2021), aiming to understand the cultural values associated with the participants involved in the study.

- $\quad$ Power distance (PDI): this dimension indicates the degree to which a society accepts the unequal distribution of power in institutions and organizations. A high PDI indicates that inequalities are considered normal, while a low PDI indicates that society expects everyone to have the same rights. With a PDI of 67 , Colombia scores high on the scale. It is therefore a society that believes that inequalities amongst people are simply a fact of life.

- Uncertainty avoidance (UAI): this dimension indicates the degree to which members of a society feel uncomfortable in new, unclear, unknown, or unusual situations. A high UAI indicates that members of society have a low tolerance towards changes. This is when it becomes necessary to follow rules, laws and regulations. A low UAI indicates less concern about risks. Changes are easier to accept, and there is a greater tolerance to alternative opinions and behaviors. With a UAI of 80 , Colombia has a high score on Uncertainty Avoidance. This means that, as a nation, they are seeking mechanisms to avoid ambiguity.

- Individualism (IDV): this dimension indicates the degree to which the members of a society prefer to act as individuals rather than as members of a community. A high IDV indicates that individuality and individual rights are above the collective. A low IDV indicates that society is collectivist and that, if necessary, individual rights are waived for the collective well-being (family, friends, etc.). With an IDV score of 13, Colombia has one of the lowest Individualism scores. In other words, it lies amongst the most collectivistic cultures in the world.

- Masculinity (MAS): this dimension indicates the degree to which the members of a society prefer values such as success, assertiveness, performance, and competence 
over quality of life, service, personal relationships, and solidarity. The first values are associated with male gender roles and the second with female. Thus, a high IDV indicates masculine society and a low IDV a more feminine one. With an IDV of 64, Colombia is a masculine society-highly success-oriented and driven. Colombians are competitive and status-oriented, yet rather collectivistic.

- Long-term orientation (LTO): this dimension indicates the degree to which the members of a society orient their life in time. A high LTO indicates that society values long-term commitments where perseverance and persistence allow them to achieve goals. A low LTO indicates that society does not reinforce the concept of long-term orientation, preferring to maintain established traditions and norms. With a low LTO of 13, Colombian culture is classified as normative. They exhibit great respect for traditions, a relatively small propensity to save for the future, and a focus on achieving quick results.

- Indulgence (IVR): this dimension indicates the degree to which the members of a society allow themselves the gratification associated with the basic and natural human impulses related to life and fun. A low LTO indicates that society suppresses the satisfaction of needs and regulates them through social norms. Scoring a very high 83 in this dimension, Colombia is shown to be an Indulgent country. They possess a positive attitude and have a tendency towards optimism. In addition, they place a higher degree of importance on leisure time, acting as they please and spending money as they wish.

\section{Materials and Methods}

\subsection{Methodology}

According to the objectives proposed, this research has been described with a mixed approach. According to Abowitz and Toole (2010) [34], descriptive studies aim to detail the properties, features and profiles of people, communities, objects, or processes that are put to the test. This is done in order to accurately show the different angles and dimensions of the phenomenon to be analyzed. Mixed methods incorporate a set of systematic, empirical, and critical research processes that involve the collection and analysis of quantitative and qualitative data. They make inferences about the product of all information collected and achieve a greater understanding of the phenomenon under study.

Since the theoretical types of mathematical knowledge were first characterized, it was possible to use the sequential transformative design [35]. These types allowed the identification of the kind of knowledge that students acquire.

\subsection{Participants}

The group studied was the distance learning students in their 3rd and 4th semesters at the Faculty of Science and Technology at Universidad Santo Tomás. These students were studying linear algebra during the second semester of 2020. A simple random population sampling was made, with a total of 61 students belonging to different regions of the country. Students were involved in both branches of the study (quantitative and qualitative). According to the student characterization carried out by the University's Office of Well-being, these students belong to social strata 2 and 3. Colombians are stratified into six socio-economic layers, where number 6 is the highest layer. The student's ages range between 17 and 38 years. Seventy-five percent of students in the sample are female. Participation was free and voluntary. The study is approved by the Ethics Committee of Universidad Internacional Iberoamericana.

\subsection{Variables}

The variables of the study were established in accordance with the bibliographic review and were grouped into three categories.

- Production of Mathematical Knowledge: The learning that a student acquires in distance education does not correspond to the reproduction or memorization of 
content proposed by the institution. Instead, it requires a rehashing of such content by the student. Thus, the present category is understood as the process of reconstruction of the content, autonomously and independently done by the student.

- Types of Knowledge: there are different classifications of the types of knowledge in mathematics. The classification that was used in this research was the proposal in [36].

- Cultural Dimensions: The Model of Cultural Dimensions of Hofstede has already been applied to the educational field [5,37], where the characteristics of each dimension presented in the relationship between teacher and student and between student and student, types of teaching, and behavioral models present in classrooms and the function of each academic space inside the curriculum were established. The cultural dimensions were already defined on the previous section. All except Indulgence were used in this study.

- Power distance (PDI): in the educational context, it measures the distance between teacher and student, as well as the consequences in the learning process. It is also related to the type of communication (unidirectional, bidirectional) in class.

- Uncertainty Avoidance (UAI): measures the way in which conflicts in the classroom are solved, that is, the conflict-solving structure and planning.

- Individualism (IDV): measures levels of formality, group organization, student initiatives, and types of communication. Individualist cultures allow students to be free to speak before the class. In a collectivist culture, students speak upon the teacher's request.

- Masculinity (MAS): measures competitiveness and solidarity amongst students. Focus is placed on performance and academic success. In Masculine cultures, students value the academic reputation of their teachers. Feminine cultures value kindness and sympathy.

- $\quad$ Long-term orientation (LTO): measures the importance given to studying as a tool for the future of a person or as an activity to enjoy. Analytical thinking is predominant in long-term-oriented cultures. Synthetic thinking is common in cultures lacking LTO.

- Indulgence (IVR): measures social and individual acceptance of fun and leisure. This index was not included in the present study.

\subsection{Instruments}

There were three instruments obtained by a participating observer:

- Instrument 1 (linear algebra exercises). This test was described by the authors. It contains exercises on specific topics of linear algebra. It was presented to students after the first synchronous meeting, when the students completed their first four weeks of work. It was an autonomous and independent activity. The questionnaire contained 13 exercises. Five were used to collect information about declarative knowledge, five for procedural knowledge, and six and twelve for conditional knowledge. Each exercise was designed for a specific purpose. A heading showed the types of knowledge associated with each. The test was validated, obtaining a Cronbach's alpha of 0.958 . This indicated that the instrument had a high level of reliability.

- Instrument 2 (Inventory of Learning Strategies). The questionnaire of 55 items was adapted for Chile [38] from the Inventory of Learning Strategies [39]. It allows the identification of learning strategies that students use with ad hoc questions. Each question describes their perception of the construction of knowledge and how it is validated.

The questionnaire has four groups of questions: deep processing (6 questions), elaborative processing (5 questions), surface processing (4 questions), and methodical study ( 2 questions). The average time needed by the students to answer was $20 \mathrm{~min}$. To validate these data, the Cronbach alpha obtained was 0.936 , indicating that the instrument had a high level of reliability. 
- Participant observation. The students gave their consent to freely participate in an attempt to be observed without affecting their spontaneous behavior. In accordance with the objectives proposed, the specific elements observed were the social and human environment (interactions and their frequency), individual and collective activities (what they do, how they do it and when), and the artifacts that the participants use (functions), based on the ideas proposed in Angrosino and Rosenberg (2012). Since students are the protagonists of their learning in this educational modality, at each synchronous encounter, broad and descriptive answers were consistently given to questions asked by the tutor. As Cubero and Ignacio (2010) mention that the speech present in classroom interactions not only transmits messages but also describes the activity where meanings are built. Recordings of synchronous-type tutorial meetings scheduled by the institution through video conference were made in order not to lose the observer approach. Each meeting had an approximate duration of two hours. The student-teacher and student-student interactions were specifically transcribed.

\subsection{Data Analysis}

The mixed approach to this research included the following approaches to data analysis:

- Participant observation: analysis units were established according to the Sam Leles (1967) [40] interaction analysis system. This is a very popular system thanks to its reliability and validity. The units of analysis are detailed in Table 1.

- Objective test: The categories proposed by Fernandez-Plaza and Simpson (2016) [41] were used for the analysis of these data. It uses a rubric (Table 2) that contemplates the levels of scope and development of the types of declarative, procedural, and conditional knowledge. The presence of the categories was coded according to a scale from 0 to 4 points, where four corresponds to the highest evaluation, and zero is the lowest.

- Inventory of learning strategies: since this instrument used a Likert-type scale, scores were calculated for each student and each item. Later, a descriptive statistical analysis of frequencies was carried out. Since in a normal distribution $68.26 \%$ of the data are found within a standard deviation, we proceeded to divide the data distribution into three segments. These will correspond to levels weak, medium, and solid, which are used to classify the students.

Table 1. Interaction analysis units.

\begin{tabular}{|c|c|c|}
\hline Category & Subcategory & Analysis Units \\
\hline \multirow{4}{*}{ Interactions } & Tutor-student & $\begin{array}{l}\text { (1) Tutor encourages actions or behaviors of students } \\
\text { (2) Tutor accepts or uses ideas suggested by students. } \\
\text { (3) Tutor answers questions asked by students. } \\
\text { (4) Tutor asks converging questions about content or procedures. } \\
\text { (5) Tutor asks diverging questions about content or procedures. }\end{array}$ \\
\hline & Student-Tutor & $\begin{array}{l}\text { (6) Students initiate discussions or ask questions. } \\
\text { (7) Students answer converging questions made by the tutor } \\
\text { (8) Students answer diverging questions made by the tutor }\end{array}$ \\
\hline & Student-student & (9) Students respond to each other, correct each other, or reach agreements. \\
\hline & & (10) Silences \\
\hline
\end{tabular}


Table 2. Reach and development levels rubric.

\begin{tabular}{|c|c|c|}
\hline Type of Knowledge & Levels & Categorires \\
\hline \multirow{3}{*}{ Declarative Knowledge } & First Level & $\begin{array}{l}\text { Terminology } \\
\text { Notation } \\
\text { Results }\end{array}$ \\
\hline & Second Level & $\begin{array}{l}\text { Concepts } \\
\text { Relationship between concepts }\end{array}$ \\
\hline & Third Level & Mathematical structure \\
\hline \multirow[t]{3}{*}{ Procedural Knowledge } & First Level & $\begin{array}{l}\text { Operations } \\
\text { Rules/properties } \\
\text { Algorithms }\end{array}$ \\
\hline & Second Level & Reasoning \\
\hline & Third Level & Strategies \\
\hline \multirow[t]{3}{*}{ Conditional Knowledge } & First Level & $\begin{array}{l}\text { Terminology } \\
\text { Notation } \\
\text { Conventions } \\
\text { Operations } \\
\text { Rules/properties } \\
\text { Algorithms }\end{array}$ \\
\hline & Second Level & $\begin{array}{l}\text { Concepts } \\
\text { Reasoning }\end{array}$ \\
\hline & Third Level & $\begin{array}{l}\text { Mathematical structure } \\
\text { Strategies }\end{array}$ \\
\hline
\end{tabular}

\section{Results and Discussion}

The construction of knowledge is not a dichotomous variable but part of a process. Thus, we will discuss whether a student has reached different phases of the developement of comprehension. The results below describe how students develop the construction of knowledge. It bears in mind the kind of knowledge produced by students in higher distance education considering the cultural characteristics of the country.

\subsection{Development of the Construction of Mathematical Knowledge}

During the synchronous meetings, the majority of tutor-student and student-tutor interactions were observed. Converging and diverging questions were formulated by the tutor, followed by the questions or conversation initiatives by students. Figure 1 shows how many times these interactions took place (horizontal axis) for each one of the analysis units (vertical axis) mentioned in Table 1 . This count of analysis units applies to each of the three tutoring sessions that took place. This shows how the frequencies did not vary significantly from session to session. Analysis unit 7 (Students answer converging questions made by the tutor) and 4 (Tutor asks converging questions about content or procedures) clearly dominate the sessions.

Within the observed interactions, several moments and/or actions that show the processes and/or reflections of students were identified. First, the students face a cognitive conflict between their prior and new knowledge. When asking students about the periods of silence that were generated through specific questions about the proposed theme, most mentioned that they did not know what to do and felt confused. Next, some of their answers and expressions were:

Student 5: I do not know what to do, I do not understand.

Student 23 (repeatedly asked): What do I have to do?

Student 41: Where do I start? 


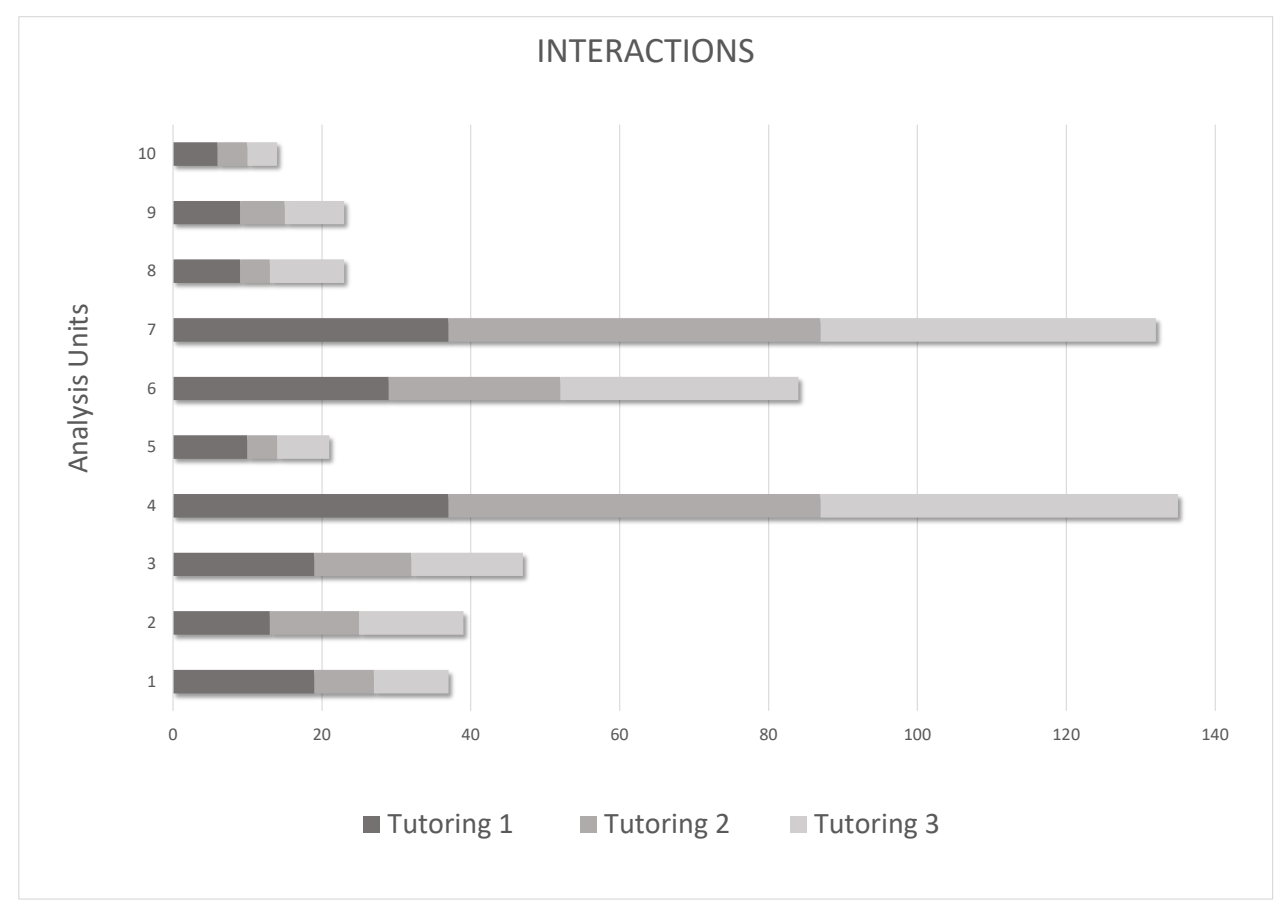

Figure 1. Graphical representation of the interactions per unit (colors represent types of tutoring (1, 2 and 3)).

While a few students searched for individual or collective guidance, the majority initiated conversation in the video conference with investigative questions and reflections, seeking approval by the tutor and colleagues:

Student 51: The order must be correct to do the calculation, right?

Student 17: I wrote the exercise on my notebook and realized that these [matrices] cannot be added.

The actions and behaviors observed at this point can be explained with Hofstead's cultural model. With a 67-point PDI, there is a wide distance of power. Students expect the tutor to be in charge of the learning process. Thus, they assume a passive role. This also explains the high tendency towards unidirectional interactions over bidirectional or multidirectional ones. Similarly, with an indicator of 80 points, Colombia has a strong UAI. This shows that students do not feel comfortable in open situations and group discussions. They expect structured learning settings, and their concern is focused on obtaining and, upon request, providing correct answers.

When students expand their ideas, some resort to different means to validate them. When asking specifically what they did, what information they took into account, or what they plan to do when solving an exercise, many resorted to definitions, properties, or previously worked processes. This is a fragmented way of identifying the necessary elements to achieve their objective.

Student 5: They are of the same order, so now we just need to calculate

Student 23: In the exercise we did before we said that the columns here should be the same as the rows there

Student 17: I multiplied and got equations, but in the book there are no similar examples. Am I doing it right?

There are two different actions here:

- Exploration by describing which elements should be taken into account.

- The identification of what it takes to solve the exercise.

These actions sought the validation of the tutor first, then that of other classmates. The interventions of the students in this phase were more spontaneous. Those students 
who spoke were competitive about providing fast answers to the questions posed. These behaviors can also be explained with the UAI dimension, as it refers to how the sensation of uncertainty, and ambiguity is related to the behaviors of the students towards the construction of knowledge by focusing directly on the constant validation of the tutor to obtain correct answers. The competition amongst those giving answers is better explained under the MAS dimension. When students manage to relate prior knowledge with new knowledge, some of them express the satisfaction akin to reaching their goal:

Student 3: The equal sign means that I can equate, and then I have equations.

Student 10: I place the problem data in a matrix and then I can calculate them.

Student 28: I understood, the right must be equal to the left, to do as we did before.

Encouraging certain behaviors from the students and using their proposals to solve situations favored a friendly learning environment. Only $20 \%$ of students freely expressed themselves when they were invited and contributed to the collective construction of knowledge. This percentage coincides with the Colombian characteristic of being collectivist. Students are generally not keen to participate in class. Since there is consensus in the group, they try to acquire knowledge that improves their social status.

\subsection{Types of Mathematical Knowledge Acquired by the Students}

Taking the learning strategies of students and the fact that in a normal distribution $68.26 \%$ of the data are within a standard deviation a three-interval segmentation is done. Thus, students are classified into three levels: weak, medium, and strong. The items related to deep processing an average of 192,787 with a standard deviation of 308,292 . A $75 \%$ adjustment was made to the standard deviation, and 17 students were classified as weak, 33 medium, and 11 strong. For items related to elaborative processing, with an average of 236,230 and a standard deviation of 381,298 , a $75 \%$ adjustment was made to the standard deviation yielding 17 weak students, 31 at average, and 13 strong.

For items related to surface processing, with an average of 113,770 and a standard deviation of 224,473, a $75 \%$ adjustment was made to the standard deviation, yielding 21 weak students, 31 average, and 9 strong. For items related to methodical study, with average of 12 and a standard deviation of 208,167 , a $75 \%$ adjustment was made to the standard deviation yielding 16 weak students, 35 average, and 10 strong.

A joint classification when contemplating the three processing factors was carried out. Fifteen students are classified as surface processing, thirty-four as elaborative processing, and twelve as deep processing. This shows a preference towards the learning strategies based on how the information is processed in order to be more specific and relevant. In relation to Hofstede's cultural dimensions, these preferences can be explained via the UAI. Students feel more comfortable in structured and non-open contexts. Their ability to personalize, visualize, and specify the information takes precedence over their abstraction skills. Likewise, the low score in the long-term dimension explains why students do not focus on future goals but on immediate ones. The fact that Colombia is a collectivist country explains why students feel that the purpose of education is to know how to do something.

Regarding the types of knowledge, in the declarative type of knowledge, it was found that $67 \%$ of the first, second, third, and sixth variables obtained a score equal to four points. The fourth variable obtained in $69 \%$ of cases a score equal to or greater than 3.6 points, while the fifth variable obtained in $66 \%$ of cases a score equal to or greater than 3.6 points. The variables that presented greater dispersion in their scores were the third and fifth, which was mainly due to arithmetic difficulties and the difficulty relating arithmetic concepts with algebraic ones. Scores equal to or greater than 3.6 points were distributed in $79 \%$ in the first level, $70 \%$ in the second level, and $85 \%$ in the third level. In terms of student classification, $69 \%$ of the participants obtained a score equal to or greater than 3.6 points.

Regarding procedural knowledge, it was found that $33 \%$ of the first and fifth variables obtained a score equal to four points, $31 \%$ of the second and fourth variables obtained a score equal to four points, and $18 \%$ of the third variable obtained a score equal to four points. This type of knowledge compared to the declarative one shows greater dispersion in each 
of the variables. Scores equal to or greater than 3.5 points were distributed in $39 \%$ in the first and second level and 34\% in the third level. In terms of student classification, 39\% of the participants obtained a score equal to or greater than 3.5 points, while $27 \%$ obtained a score between 0.5 and 2.4 points.

Regarding conditional knowledge, it was found that variables 12, 13, 14, and 20 obtained a score equal to four points corresponding to $70 \%$ of the observations; variables $15,16,18$, 19 , and 21 obtained a score around $50 \%$ of the observations; and variable 17 obtained the lowest percentage in this score $(39 \%)$. This type of knowledge versus the declarative and procedural show a great concentration around a score of two points.

In terms of student classification, $49 \%$ of the participants obtained a score equal to or greater than 3.5 points, while $32 \%$ obtained a score between 0.5 and 2.4 points. In short, students build declarative knowledge more easily. This, associated with Hofstede's cultural dimensions can possibly be explained by the high score in the UAI dimension, since students do not feel comfortable with open situations and require training, norms, or rules that allow their answers to be justified. It is also directly associated with normative knowledge. Likewise, it is possible that the development of procedural and conditional knowledge is affected by the discomfort that the different routes to solve an exercise brings.

\section{Conclusions}

This article characterized the mathematical knowledge acquired by higher distance education students in a Colombian institution during the development of a linear algebra course. It was possible to identify how students develop the construction of mathematical knowledge, as well as what type of mathematical knowledge they produce from a referential framework built from the works of Johnson (2005) [27] and its relationship with the cultural characteristics of Colombia from the Hofstede model [25].

Faced with the question of how students build knowledge and taking into account Cubero and Ignacio (2011) [32], we were able to identify, through the analysis of the interactions observed in synchronous encounters, several in-class events that interdependently influence each other. The first event was characterized by the cognitive conflict that students face between prior and new knowledge. The students hope that their tutor remains in charge of their learning and guides them in the steps to follow. They also assume a not very participatory attitude. The second event happens when students manage to expand their constructs and use different sources that allow them to validate their ideas. They use the exploration and identification of the necessary and sufficient elements to answer a question. Many of the students look to their conceptual prior knowledge for these elements (definitions, properties, theorems) and constantly seek the validation of their tutor, whom they deeply respect. In the third event, students are able to relate previous knowledge with new. Upon reaching this phase, they express satisfaction. Here it was very important to review the environment as a means to promote a friendly and collective construction of knowledge setting. This coincides with Prados and Cubero (2013) [33].

Regarding the learning strategies that students used consciously, a great inclination was found towards those based on the way in which information is processed. These strategies relate to an elaborative process where students build from examples that they manage to express in their own words and not in a formal language. Under these strategies, the ability to personalize, specify, and visualize information is more important than the ability to abstract. Comparing this with the study carried out by Acevedo et al. (2009) [42] in Chile, the learning strategy prioritized by university students corresponds to deep processing, while elaborative processing is almost absent. From Hofstede's model, these two countries differ in the cultural dimension of masculinity/femininity, since in Chile the dominant values are caring for others and quality of life.

When faced with the question of the type of knowledge that students build, a trend towards declarative knowledge was found. When related to the interactions observed in synchronous encounters, it shows correspondence with the characteristics of the second event. The next type of knowledge developed is the procedural one, which has a close 
relationship with the means of validation that students use when searching for videos that allow them to understand the algorithmic way of solving proposed situations. Finally, there is the development of conditional knowledge, which is also related to the silent times of synchronous encounters, the types of videos that students use for validation, and the learning strategies they use.

The way in which students build knowledge and the type of knowledge built is related to the cultural characteristics of Colombia as it is a nation with a wide distance of power. This indicates a passive attitude of the students and great respect for the tutor. Thus, the educational system revolves around the tutor. The high degree of collectivism explains why students only participate when they feel that they have the approval of the group. They do not show individual initiative and are grouped according to their interests or regions. Colombia is a masculine society, which implies the presence of competitive students who seek to excel in the group. School failure is synonymous with something disastrous. On the other hand, the strong avoidance of uncertainty manifests when students are not open to discussions or debates. They are not receptive to tutorials with a flipped classroom model. The orientation towards the short-term goals explains the preference for traditional tutorials. Students prefer the development of a synthetic thought over an analytical one. Success is attributed to elements unrelated to effort.

This study has provides a snapshot of the construction of mathematical knowledge in the higher distance education setting, although the findings should be viewed with some caution. The study's findings were obtained from an open university sample with a videoand text-based learning model and both synchronous and asynchronous communication between the main actors (students and instructors). Therefore, the results may be specific to this type of environment. Conclusions drawn from the study may be used to improve teaching and learning practices in similar learning contexts. Results are, however, coherent with the social and cultural context in which this learning takes place.

Subsequent studies should bear in mind that direct control over distance education students is not the same as that in regular education. The design of instruments must consider the cultural characteristics of the population as it has direct implications in the way in which the social construction of knowledge develops. Although this study expanded our knowledge about the production of mathematical knowledge, we must recognize that the lockdown of the SARS-CoV-2 pandemic affected all educational systems. Furthermore, the data of this article were obtained at a private institution. Results specific to this environment may also affect the data. Future research should take advantage of this study and expand the educational contexts (private and public) and the sample size.

Author Contributions: Conceptualization, E.M.-V. and I.L.-C.; Methodology, E.M.-V. and I.L.-C.; Software, D.B.-A. and F.F.-N.; Validation, D.B.-A., F.F.-N. and I.L.-C.; Formal analysis, E.M.-V.; Data curation, D.B.-A.; Writing —original draft preparation, E.M.-V. and D.B.-A.; Writing—review and editing, I.L.-C. and F.F.-N. All authors have read and agreed to the published version of the manuscript.

Funding: The research work of F.F.-N. is funded by the Spanish Ministry of Science under Project ENE2017-88889-C2-1-R. The research work of F.F.-N., I.L.-C. and D.B.-A. has been supported in part by the Spanish SEPIE and the Erasmus+ Programme under Project 2020-1-ES01-KA226-HE-094952.

Institutional Review Board Statement: The study was approved by the Institutional Review Board of Universidad Loyola Andalucía.

Informed Consent Statement: Informed consent was obtained from all subjects involved in the study.

Data Availability Statement: The data that support the findings of this study are available from the corresponding author, [elizabeth.martinez@ustadistancia.edu.co], upon reasonable request.

Conflicts of Interest: The authors declare no conflict of interest. 


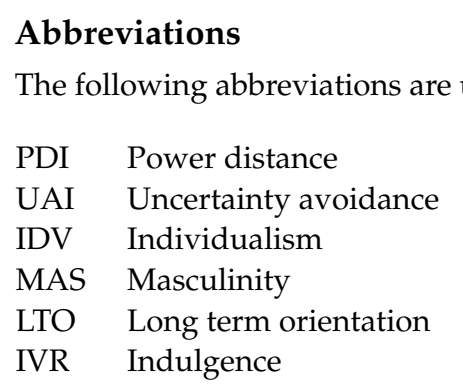

\section{References}

1. Assunção Flores, M.; Gago, M. Teacher education in times of COVID-19 pandemic in Portugal: National, institutional and pedagogical responses. J. Educ. Teach. 2020, 46, 507-516. [CrossRef]

2. Mohamad Nasri, N.; Husnin, H.; Mahmud, S.N.D.; Halim, L. Mitigating the COVID-19 pandemic: A snapshot from Malaysia into the coping strategies for pre-service teachers' education. J. Educ. Teach. 2020, 46, 546-553. [CrossRef]

3. Gómez-Rey, P.; Fernández-Navarro, F.; Vázquez-De Francisco, M.J. Identifying Key Variables on the Way to Wellbeing in the Transition from Face-to-Face to Online Higher Education due to COVID-19: Evidence from the Q-Sort Technique. Sustainability 2021, 13, 6112. [CrossRef]

4. Deepwell, F. Embedding quality in e-learning implementation through evaluation. J. Educ. Technol. Soc. 2007, 10, 34-43.

5. Gómez-Rey, P.; Barbera, E.; Fernández-Navarro, F. Measuring teachers and learners' perceptions of the quality of their online learning experience. Distance Educ. 2016, 37, 146-163. [CrossRef]

6. Shelton, K. A review of paradigms for evaluating the quality of online education programs. Online J. Distance Learn. Adm. 2011, $4,1-11$.

7. Auster, C.J. Blended learning as a potentially winning combination of face-to-face and online learning: An exploratory study. Teach. Sociol. 2016, 44, 39-48. [CrossRef]

8. Gregori, P.; Martínez, V.; Moyano-Fernández, J.J. Basic actions to reduce dropout rates in distance learning. Eval. Progr. Plan. 2018, 66, 48-52. [CrossRef]

9. Grau-Valldosera, J.; Minguillón, J. Redefining dropping out in online higher education: A case study from the UOC. In Proceedings of the 1st International Conference on Learning Analytics and Knowledge, Banff, AL, Canada, 27 February-1 March 2011; pp. 75-80.

10. Sweet, R. Student dropout in distance education: An application of Tinto's model. Distance Educ. 1986, 7, 201-213. [CrossRef]

11. Ajzen, I.; Fishbein, M. Attitude-behavior relations: A theoretical analysis and review of empirical research. Psychol. Bull. 1977, 84, 888. [CrossRef]

12. Spady, W.G. Dropouts from higher education: An interdisciplinary review and synthesis. Interchange 1970, 1, 64-85. [CrossRef]

13. Yukselturk, E.; Inan, F.A. Examining the factors affecting student dropout in an online certificate program. Turk. Online J. Distance Educ. 2006, 7, 76-88.

14. Park, J.H.; Choi, H.J. Factors influencing adult learners' decision to drop out or persist in online learning. J. Educ. Technol. Soc. 2009, 12, 207-217.

15. Rienks, J.; Taylor, S. Attrition and academic performance of students identified as at-risk using administrative data alone. In First Year in Higher Education Conference; Citeseer: University Park, PA, USA, 2009.

16. Parker, A. A study of variables that predict dropout from distance education. Int. J. Educ. Technol. 1999, 1, 1-10.

17. Mora, R.H.; Araya, R.G.; Sánchez, M.C. Deserción y reprobación, desde el enfoque del estudiantado en la educación superior, en el curso de Matemática General. Rev. Comun. 2019, 28, 17-37.

18. Guzmán Rincón, A.; Barragán, S.; Cala Vitery, F. Rurality and Dropout in Virtual Higher Education Programmes in Colombia. Sustainability 2021, 13, 4953. [CrossRef]

19. Vygotsky, L.S. Mind in Society: The Development of Higher Psychological Processes; Harvard University Press: Cambridge, MA, USA, 1980.

20. Fayol, M.; Thevenot, C. The use of procedural knowledge in simple addition and subtraction problems. Cognition 2012, 123, 392-403. [CrossRef]

21. Crooks, N.M.; Alibali, M.W. Defining and measuring conceptual knowledge in mathematics. Dev. Rev. 2014, 34, 344-377. [CrossRef]

22. Eaves, J.; Attridge, N.; Gilmore, C. Increasing the use of conceptually-derived strategies in arithmetic: Using inversion problems to promote the use of associativity shortcuts. Learn. Instr. 2019, 61, 84-98. [CrossRef]

23. Dubé, A.K. Adolescents' understanding of inversion and associativity. Learn. Individ. Differ. 2014, 36, 49-59. [CrossRef]

24. Chinnappan, M.; Forrester, T. Generating procedural and conceptual knowledge of fractions by pre-service teachers. Math. Educ. Res. J. 2014, 26, 871-896. [CrossRef]

25. Hofstede, G. Culture's Consequences: Comparing Values, Behaviors, Institutions and Organizations across Nations; Sage Publications: Thousand Oaks, CA, USA, 2001.

26. Phye, G.D. Handbook of Academic Learning: Construction of Knowledge; Elsevier: Amsterdam, The Netherlands, 1997. 
27. Johnson, S. Conceptual and procedural knowledge in mathematics: An introductory analysis. Concept. Proced. Knowl. Case Math. 2005, 91, 175-189.

28. Star, J.R. Reconceptualizing procedural knowledge. J. Res. Math. Educ. 2005, 36, 404-411.

29. Baroody, A.J.; Feil, Y.; Johnson, A.R. Research commentary: An alternative reconceptualization of procedural and conceptual knowledge. J. Res. Math. Educ. 2007, 38, 115-131.

30. Rittle-Johnson, B.; Schneider, M.; Star, J.R. Not a one-way street: Bidirectional relations between procedural and conceptual knowledge of mathematics. Educ. Psychol. Rev. 2015, 27, 587-597. [CrossRef]

31. Rittle-Johnson, B.; Alibali, M.W. Conceptual and procedural knowledge of mathematics: Does one lead to the other? J. Educ. Psychol. 1999, 91, 175. [CrossRef]

32. Cubero, R.; Ignacio, M.J. Accounts in the Classroom: Discourse and the Coconstruction of Meaning. J. Constr. Psychol. 2011, 24, 234-267. [CrossRef]

33. Prados, M.; Cubero, M. Reflecting on how to study the teaching-learning process in the natural context of the university classroom. Cult. Educ. 2013, 25, 273-284. [CrossRef]

34. Abowitz, D.A.; Toole, T.M. Mixed method research: Fundamental issues of design, validity, and reliability in construction research. J. Constr. Eng. Manag. 2010, 136, 108-116. [CrossRef]

35. Kroll, T.; Neri, M. Designs for mixed methods research. Mix. Methods Res. Nurs. Health Sci. 2009, 31, 31-49.

36. Schraw, G.; Crippen, K.J.; Hartley, K. Promoting self-regulation in science education: Metacognition as part of a broader perspective on learning. Res. Sci. Educ. 2006, 36, 111-139. [CrossRef]

37. Gómez-Rey, P.; Barbera, E.; Fernández-Navarro, F. The impact of cultural dimensions on online learning. J. Educ. Technol. Soc. 2016, 19, 225-238.

38. Pérez-Fuentes, F.; Truffello-Camponovo, I. Diseño y Evaluación de Actividades Intruccionales Conducentes a las Estrategias de Aprendizaje Elaborativa y Profunda. Rev. Enfoques Educ. 2017, 1. [CrossRef]

39. Geisler-Brenstein, E.; Schmeck, R.R. The revised inventory of learning processes: A multifaceted perspective on individual differences in learning. In Alternatives in Assessment of Achievements, Learning Processes and Prior Knowledge; Springer: Berlin/Heidelberg, Germany, 1996; pp. 283-317.

40. Leles, S. Evolving a Theory of Effectiveness in Education; The Ohio State University: Columbus, OH, USA, 1967.

41. Fernández-Plaza, J.A.; Simpson, A. Three concepts or one? Students' understanding of basic limit concepts. Educ. Stud. Math. 2016, 93, 315-332. [CrossRef]

42. Pierart, C.G.A.; Salgado, M.T.C.; Valdebenito, V.M.; Palma, H.M. Estrategias de aprendizaje en alumnos universitarios y de enseñanza media. Rev. Estilos Aprendiz. 2009, 2. Available online: https://revista.ieee.es/index.php/estilosdeaprendizaje/ article/view/893 (accessed on 23 July 2021). 